\title{
Structural Basis for the Inhibition of IAPP Fibril Formation by the Hsp60 Co-Chaperonin Prefoldin
}

\author{
Authors: Ricarda Törner ${ }^{1, \#}$, Tatsiana Kupreichyk ${ }^{2,3, \#}$, Lothar Gremer ${ }^{2,3,4}$, Elisa Colas Debled ${ }^{1}$, \\ Daphna Fenel $^{1}$, Pierre Gans ${ }^{1}$, Dieter Willbold ${ }^{2,3,4}$, Guy Schoehn ${ }^{1}$, \\ Wolfgang Hoyer ${ }^{2,3, *}$, Jerome Boisbouvier ${ }^{1, *}$
}

Affiliation:

1 Univ. Grenoble Alpes, CNRS, CEA, Institut de Biologie Structurale (IBS), 71, Avenue des Martyrs, F-38044 Grenoble, France.

2 Institute of Biological Information Processing (IBI-7: Structural Biochemistry) and JuStruct: Jülich Center for Structural Biology, Forschungszentrum Jülich, 52425 Jülich, Germany

3 Institut für Physikalische Biologie, Heinrich-Heine-Universität Düsseldorf, 40225

Düsseldorf, Germany

4 Research Center for Molecular Mechanisms of Aging and Age-Related Diseases, Moscow Institute of Physics and Technology (State University), Dolgoprudny, Russia

\# These authors contributed equally

* correspondence to be addressed to wolfgang.hoyer@uni-duesseldorf.de or jerome.boisbouvier@ibs.fr

\section{ORCID list:}

Jerome Boisbouvier 0000-0003-3278-3639

Wolfgang Hoyer 0000-0003-4301-5416

Tatsiana Kupreichyk 0000-0002-5151-6424

Ricarda Törner 0000-0002-0775-2075

Lothar Gremer 0000-0001-7065-5027

Dieter Willbold 0000-0002-0065-7366

Guy Schoehn 0000-0002-1459-3201

Daphna Fenel 0000-0002-9193-9827

Elisa Colas Debled 0000-0002-8279-3053

Pierre Gans 0000-0002-0697-6552 


\section{Abstract:}

Chaperones, as modulators of protein conformational states, are key cellular actors to prevent the accumulation of fibrillar aggregates. Here, we integrated kinetic investigations with structural studies to elucidate how the ubiquitous co-chaperonin prefoldin (PFD) inhibits diabetes associated islet amyloid polypeptide (IAPP) fibril formation. We demonstrated that both human and archaeal PFD interfere similarly with the IAPP fibril elongation and secondary nucleation pathways. Using archaeal prefoldin model, we combined NMR spectroscopy with EM to establish that the inhibition of fibril formation is mediated by the binding of prefoldin's coiledcoil helices to the flexible IAPP N-terminal segment accessible on the fibril surface and fibril ends. AFM demonstrates that binding of prefoldin to IAPP leads to the formation of lower amounts of aggregates, composed of shorter fibrils, clustered together. Linking structural models with observed fibrillation inhibition processes opens new perspectives for understanding the interference between natural chaperones and formation of disease-associated amyloids.

key words: Amylin; IAPP; chaperone; prefoldin; fibril formation; amyloid; protein structure. 


\section{Introduction}

To date there are about 50 proteins or peptides identified which are implicated in amyloid diseases ${ }^{1}$. The hallmark of these pathologies is the formation of thermodynamically highly stable fibrils with a characteristic $\beta$-cross structure ${ }^{1,2}$ from native monomeric proteins. Most studied amyloidogenic proteins are involved in neurodegenerative diseases such as Alzheimer's or Parkinson's disease ${ }^{3}$. However, the cell-toxic formation of fibrillar aggregates can also be of systemic nature or localized in peripheral organs and can be associated with very different diseases such as arthritis or diabetes ${ }^{4}$. The 37 amino-acids long intrinsically disordered peptide hormone islet amyloid polypeptide (IAPP) ${ }^{5}$, also known as amylin, is found as amyloid aggregates surrounding $\beta$-cells in the pancreas in $90 \%$ of type II diabetes cases ${ }^{6,7}$. A variety of ways have been identified how amyloids can confer toxic activities, as for example the increase of the permeability of cell membranes by oligomers of amyloidogenic proteins ${ }^{8}$, and formation of porous structures ${ }^{9}$. Likewise, in the case of IAPP, not mature fibrils but small oligomeric species formed as intermediates during the fibrillation process have been observed to be the most toxic for $\beta$-cells ${ }^{10}$. Nevertheless, the mature amyloid fibrils, whose structures have recently been elucidated for IAPP ${ }^{11-15}$ are not innocuous as they can sequester proteins of the cell machinery ${ }^{16,17}$, exert mechanical stress on the cell ${ }^{1}$, and play a significant catalytic role during the fibril formation process ${ }^{18}$.

The fibrillation process starts with an oligomerization event, where a nucleus is formed, which rapidly elongates by templated incorporation of monomers. As soon as nucleation has occurred, the fibril growth proceeds exponentially since not only elongation occurs, but also 
secondary processes, such as fibril fragmentation or secondary nucleation on fibril surfaces, which increase the rate of the fibrillation process ${ }^{19}$. In vivo, under normal conditions, the protein quality control machinery composed of chaperone systems, ubiquitin-proteasome systems, and autophagy-lysosomal systems is able to prevent the formation of aggregates ${ }^{20,21}$. However, in cases of misfolding diseases, these systems are either weakened due to a decrease of capacity during aging ${ }^{16}$ or overwhelmed due to increased concentrations or moreaggregation prone mutants of amyloidogenic proteins in hereditary conditions ${ }^{4}$. A detailed mechanistic understanding of this natural quality control machinery allows for targeting its processes for medical intervention, either by targeted upregulation of its components or via functional replacement with small molecules ${ }^{22}$. Chaperone molecules as modulators of protein conformational states are key factors acting on proteins during their transition from native state to the amyloid fold ${ }^{20,23,24}$. Interacting with a multitude of species, chaperones are able to alter the fibrillation process by inhibition of aggregation, disaggregation, or detoxification ${ }^{25-28}$. For instance, fibrillation inhibition can be mediated via interaction with misfolded monomers ${ }^{29}$ or small oligomers, which prevents the formation of seeding competent nuclei, but also interaction with fibril ends ${ }^{30}$ or decoration of the fibril surface ${ }^{31}$ is possible, which inhibits elongation and secondary nucleation processes respectively. Treatment of the diseases associated with amyloidogenic proteins whose native state is intrinsically disordered remains an important challenge for modern medicine, so a better understanding of the modulation of such amyloidogenic proteins by chaperones is of paramount interest.

Here we report the mechanistic study of IAPP fibrillation inhibition by the HSP60 type II co-chaperonin prefoldin (PFD). Homologues of this co-chaperonin are found in the cytosol 
of archaeal and eukaryotic cells. The heterohexameric PFD is a holdase with a characteristic “jellyfish” architecture, consisting of a $\beta$-barrel body and coiled-coil $\alpha$-helix tentacles ${ }^{32}$.

Prefoldin binds substrates via a clamp-like mechanism and delivers it to HSP60 for refolding ${ }^{33}$. PFD has previously been shown to interact with different disease-relevant amyloidogenic substrates and to inhibit their aggregation ${ }^{34-37}$, however no structural or mechanistic insights in this process have been described heretofore. We have integrated kinetic investigations with structural studies using atomic force microscopy (AFM), electron microscopy (EM) and nuclear magnetic resonance (NMR) spectroscopy to elucidate the different inhibition pathways and to provide a structural understanding of the prefoldin-amyloid interaction. The study of the highly dynamic complex between the $90 \mathrm{kDa}$ PFD and intrinsically disordered $4 \mathrm{kDa}$ IAPP enabled us to obtain insights into the chaperoning process at sub-molecular level. We show that inhibition of elongation and secondary nucleation is achieved by the interaction of PFD with IAPP fibril ends and surface, which subsequently leads to lower fibrillation rates and to the formation of clustered aggregates instead of individual fibrils. 


\section{Results}

PFD impedes IAPP aggregation. IAPP aggregation kinetics in presence of PFD show a strong inhibitory effect of PFD on IAPP fibril formation in vitro (Fig. 1a and Supplementary Fig.

S1a). For both Pyrococcus horikoshii and human PFD (denoted as PhPFD and hPFD, respectively), the overall tendencies are highly similar. The aggregation process is affected at low sub-stoichiometric PFD concentrations, suggesting an interaction between PFD and IAPP oligomers or fibril states, rather than a simple sequestration of IAPP monomers by PFD. In de novo aggregation assays monitored by thioflavin $\mathrm{T}(\mathrm{ThT})$ fluorescence, starting from monomeric IAPP without addition of any pre-formed aggregates, progressive addition of PFD slightly increases the duration of the lag phase (during which no aggregation is detectable by ThT fluorescence) and strongly reduces the fluorescence intensity (FI) in the final plateau phase. In addition, increased PFD concentrations result in a significant reduction of fibril growth rates associated with increased durations of the growth phase (the time span between lag phase and plateau phase) by more than an order of magnitude (Fig.1 a and Supplementary Fig. S1a).

In order to further investigate the inhibitory effects of both human and archaeal PFD on different processes contributing to IAPP aggregation, secondary nucleation and elongation assays were performed. Absence of agitation and addition of non-sonicated pre-formed fibrillar seeds enable observation of the surface-catalysed secondary nucleation process as the dominant contributor to the growth of fibrillar mass. Maximal growth rate drastically decreases for [PFD]:[IAPP] molar ratios above 1:113, and drops to almost zero for molecular ratios larger 
than 1:17. For observation of PFD's effect on elongation of IAPP fibrils, sonicated, short, preformed IAPP fibrils were added to IAPP monomers, offering a high number of fibril ends. The very first phase of linear growth reflects the pure elongation process, as it is the dominating mechanism of aggregation under this condition. Addition of PFD results in a distinct decrease of the initial growth rate (Fig. 1a). While the described effects on IAPP fibrillation are present for both archaeal and human PFD, the inhibitory effects of hPFD are more pronounced. The kinetic study of different modes of IAPP aggregation in presence of PFD shows that PhPFD and hPFD affect various steps of the fibrillation process. Sub-stoichiometric inhibition of both elongation and secondary nucleation implies interaction of PFD with IAPP fibrils, at the fibril ends and also along the fibril surface. Moreover, the final plateau values in all the kinetic experiments become significantly lowered if PFD is present.

PFD induces formation of compact aggregates. Atomic force microscopy (AFM) of the IAPP species present after the aggregation kinetics experiment showed changes in the appearance and the amount of IAPP aggregates in the presence of PFD (Fig. 1b and Supplementary Fig. S2). IAPP aggregation in absence of PFD results in a large amount of long, individually distinguishable fibrils (Fig. 1b left). In comparison, IAPP aggregates in presence of PFD are rare and rather clustered. The increase of PFD concentration lowers the overall amount of IAPP aggregates. Although the clustering gives rise to bigger assemblies of IAPP, some single fibrils are clearly visible at their perimeters (marked with arrows in Fig. 1b). Hence, this suggests that the observed clusters are not amorphous, but they represent rather bundles of shorter IAPP fibrils. 
IAPP binds PFD cavity in a dynamic manner. In order to determine the binding site of IAPP on the PFD surface, NMR binding studies were performed with PhPFD, whose NMR assignment of backbone and methyl groups is available ${ }^{38}$ (Supplementary Fig. S3).

Structurally, hPFD and PhPFD are similar ${ }^{39,40}$, but whilst hPFD is composed of six different subunits, the PhPFD complex contains $2 \alpha$ - and $4 \beta$-subunits, which simplifies the investigation of this $86.4 \mathrm{kDa}$ protein heterohexamer by solution NMR. The similar results obtained by AFM and ThT assays for the investigation of the effects of hPFD and PhPFD on IAPP fibril formation support the choice of this hyperthermophilic model system, which was used for all subsequent structural studies.

For the NMR investigation of the PhPFD-IAPP interaction, we have prepared highly deuterated complexes of PhPFD, selectively labelled on backbone $\left({ }^{15} \mathrm{~N}-{ }^{1} \mathrm{H}\right.$ probes $)$ or end of side chains $\left({ }^{13} \mathrm{CH}_{3}\right.$ probes $)$ on either $\alpha$ - or $\beta$-subunit. To determine the binding surface of IAPP on PhPFD, we prepared a spin-labelled IAPP construct, which allowed us to map the binding interface via paramagnetic relaxation enhancement $(\mathrm{PRE})^{41-43}$. The disulfide bridge between cysteines two and seven on IAPP forbids spin labelling using standard thiol-reactive nitroxy derivatives, therefore, we linked a DOTA-cycle to the N-terminus using a two- $\beta$-alanine linker. The DOTA-functionalized IAPP was loaded with paramagnetic $\mathrm{Gd}^{3+}$ (Gd-IAPP) or diamagnetic $\mathrm{Lu}^{3+}$ cations (Lu-IAPP) (Supplementary Fig. S4). Labelled PhPFD was incubated at $30^{\circ} \mathrm{C}$ with either paramagnetic Gd-IAPP or diamagnetic Lu-IAPP reference (Fig. 2a-e). The residues involved in binding with IAPP were identified by comparing the intensities of PFD's NMR signals in presence of Gd-IAPP or Lu-IAPP, respectively (Supplementary Fig. S5). 
Mapping of the paramagnetically-broadened residues on the surface of PhPFD (PDB: 2ZDI, Fig. 2f) allows to locate the binding interface between IAPP and PhPFD (Fig. 2g-j). Whilst no PRE-broadening is observed for residues which are located on the top of the $\beta$-barrel body, broadening inside the cavity and along the sides of coiled-coil helices is detected. More specifically, strong interaction is observed in the middle part of the coiled-coil helices corresponding to residues 8-31 and 118-135 of the $\alpha$-subunit. On the $\beta$-subunits the first $32 \mathrm{~N}$ terminal residues are the most strongly broadened by the Gd-IAPP. These two regions face each other in the complex. All coiled-coil regions are especially enriched with glutamine. Interestingly, the regions strongly affected by IAPP paramagnetic relaxation present a globally negatively charged surface $(-2)$ which can complement the net positive charge $(+2)$ of the IAPP sequence. Also analysis of PFD's electrostatic surface indicates that the regions strongly affected by IAPP paramagnetic relaxation are predominantly negatively charged or neutral (Supplementary Fig S6), suggesting that the electrostatic interaction may complement hydrophobic interactions, which presumably remain the main driving force for PFD-IAPP interactions. The large binding interface determined from the PRE-data suggests avidity-based binding to many lower affinity sites, which gives rise to the observed affinity. The NMR study suggests that monomeric IAPP is being incorporated in the chaperone cavity whilst binding and releasing the available interaction surfaces in a dynamic manner, as already observed for complexes involving unstructured proteins bound to other molecular chaperones ${ }^{41,44-46}$.

IAPP binds PFD with two binding segments. To determine IAPP residues involved in binding of PhPFD, we recorded $2 \mathrm{D}$ NMR ${ }^{15} \mathrm{~N}-{ }^{1} \mathrm{H}$-correlation spectra of $\mathrm{U}-\left[{ }^{15} \mathrm{~N}\right]$-labelled IAPP 
at $30^{\circ} \mathrm{C}$ after addition of increasing ratios of PFD. Quantifications of the IAPP backbone amide signal broadening and chemical shift perturbations (CSPs) in the NMR titration experiment were used to map the binding sequence (Fig. 3a-d). Strong CSPs were observed for IAPP residues 10-19 and 24-28 (Fig. 3e). Peak broadening, resulting from apparent decreased tumbling rates upon binding of the $86.4 \mathrm{kDa}$ prefoldin complex to small flexible IAPP, was located towards the N-terminus (Fig. 3d). C-terminal residues 34-37 are almost not impacted by interaction with PFD and are therefore most likely not involved in direct binding. Interestingly, binding is not restricted to the region 20-29, which is strongly involved in fibril formation and found buried in recently elucidated cryo-EM structures ${ }^{11-15}$. The spectral distribution in the proton dimension remains narrow, which suggests that IAPP does not fold upon binding, but remains essentially disordered. This confirms the PRE-results obtained upon monitoring the interaction of paramagnetically tagged IAPP on PFD which show an extended binding surface (Fig. 2). More quantitative analysis of binding strength was performed with the TITAN lineshape fitting program ${ }^{47}$, assuming a 1:1 stoichiometry. Line-shapes and change of signal frequencies were fitted for Ala13, Val17, His18, Ser19, Leu27, Phe23, Ala25, and Ser28, as these residues are important for the binding and analysis is not hampered by peak overlap. The apparent $\mathrm{k}_{\mathrm{off}}$ rate was estimated by line shape fitting to be in the order of $6000 \mathrm{~s}^{-1}$, corresponding to a residence time of IAPP on PFD in the order of 100-200 $\mu \mathrm{s}$. The apparent dissociation constant $\mathrm{K}_{\mathrm{D}}(61 \pm 3.2 \mu \mathrm{M}$ - error determined by bootstrap analysis $)$ shows that IAPP has an affinity for PFD in the low to medium range. Estimation of the dissociation constant $\mathrm{K}_{\mathrm{D}}$ by biolayer interferometry $(\mathrm{BLI})$, for which monomeric biotinylated IAPP was 
immobilized on a streptavidin sensor, gave a result in the same order of magnitude $(16 \pm 2.4$ $\mu \mathrm{M})$ (Fig. 3f).

Inhibition is mediated by PFD binding to IAPP fibril ends and surface. To understand the observed effect of substoichiometric inhibition of elongation and secondary nucleation observed in the fibrillation assays, we have investigated PFD binding to IAPP fibrils by electron microscopy (EM). The major polymorph of IAPP fibrils used for this study has a pitch of $\sim 48 \mathrm{~nm}$ (Fig. 4a-c), consistent with previous cryo-electron microscopy (cryo-EM) structure determination of IAPP fibrils (polymorph 1 in Röder et al. 2020, Fig 4d). Preformed IAPP fibrils were incubated with PFD for $30 \mathrm{~min}$, transferred to a carbon grid, stained with SST and then visualized by electron microscopy. In the electron micrographs, strong decoration of the fibril with PFD is observed (Fig. 4 e-h). Visual analysis shows that on the fibril surface approximately every $80 \mathrm{~nm}$ one PFD molecule is found, that is about $10 \%$ of the surface (Fig. 4e). Upon investigation of the fibril ends, a density was repeatedly observed towards the end of the fibrils (Fig. 4h), which suggests a binding of PFD also to the fibril termini - about $40 \%$ of ends are accompanied by a density.

To characterize this interaction further at a sub-molecular level, we have docked PFD (PDB: 2ZDI) on the previously determined cryo-EM structure of IAPP fibrils, based on experimental PRE-broadening on PFD and chemical shift perturbation detected by solution NMR between PFD and IAPP (Fig. 5d,e), using the software HADDOCK ${ }^{48,49}$. The docking procedure was either directed to the fibril surface or to the fibril ends, thereby creating two representative complex-models (Fig. 5d,e). Analysis of these models indicates that IAPP-PFD 
binding is strongly mediated by the N-terminal part of IAPP, which remains flexible and solution-exposed also in the fibrillar state, and that protruding N-termini of several neighbouring IAPP molecules can interact with the same prefoldin (up to six). This model rationalizes the pattern observed in the negative stain micrographs, as well as the inhibitory effect of PFD on IAPP fibrillation in the kinetic assays. 


\section{Discussion}

Previously, the co-chaperonin prefoldin was reported to inhibit the fibrillation of highly toxic amyloidogenic proteins in vivo and in vitro ${ }^{34-37}$, but no mechanistic or structural information was obtained so far. Here we show that prefoldin inhibits IAPP fibrillation at substoichiometric concentrations and interacts with multiple IAPP species, such as monomers and mature fibrils, and propose models for these interactions. We gained structural and mechanistic insights into the interaction of PFD with two different states of amyloidogenic IAPP (monomeric and fibrillar) by combining solution NMR, EM, AFM, and kinetic measurements.

NMR interaction studies report on binding between monomeric IAPP and PFD by chemical shift perturbations and peak broadening on IAPP. Analysis of these effects allowed us to identify two segments on IAPP, one towards the N-terminus (10-19) and one in the middle segment (24-28) to be important for the interaction (Fig. 3). Extensive deuteration and methyl labelling enabled us to study the interaction from the perspective of the $86.4 \mathrm{kDa}$ PhPFD. PREmapping with a paramagnetic-labelled IAPP construct on PFD allowed to determine the sites involved in IAPP binding (Fig. 2). As it has been previously observed for chaperone-client complexes, such as the one between Hsp90 and tau protein, the complex is characterized by a broad interaction surface ${ }^{46}$. IAPP induced PRE-broadening effects are observable inside the whole PFD cavity. Especially strong broadening is observed towards the middle of the coiledcoil helices of the $\alpha$-subunit, suggesting that this is an important region for binding. The apparent $K_{D}$ was determined to be of intermediate strength (between 16 and $61 \mu \mathrm{M}$, according to BLI and NMR investigation). The extensive binding interface and multiple binding regions 
on IAPP suggests avidity-based binding to multiple lower affinity contacts which can be sampled by IAPP. The spectra are characteristic of fast exchange between bound and free form with an apparent lifetime of the bound state on the order of 100 to $200 \mu$ s. As typical for chaperone-client complexes ${ }^{45}$, the interaction between monomeric IAPP and prefoldin cannot be described as one static complex, but as a structural ensemble where IAPP dynamically binds and unbinds the available interaction sites inside the prefoldin cavity. Possible representative models of this complex were obtained by docking of IAPP on PFD driven by NMR derived structural restraints (one of the computed models is shown in Fig. 5a,b). De novo ThTfluorescence assays show that this interaction between IAPP monomers and prefoldin does only lead to a weak effect on the lag-time. Probably, neither restructuring effects on IAPP, nor sequestration of enough IAPP monomers in PFD cavity occurs, to strongly impact the primary nucleation step, and therefore the PFD-monomer interaction would play a minor role in the inhibition mechanism of IAPP fibril formation. However, the NMR studies between monomeric IAPP and PFD bring important information about residues of IAPP and PFD susceptible to be involved in the interaction with different species during the IAPP fibrillation pathway.

The ThT-fluorescence assays (Fig. 1) show inhibition of IAPP fibrillation at substoichiometric PFD ratios, which suggests interaction between PFD and high molecular weight IAPP species (e.g., oligomers or fibrils). Further investigation of fibrillation pathways by seeded ThT assays showed that both elongation and secondary nucleation pathways were inhibited by the presence of PFD (both human and archaeal). The subsequently performed EM analysis allowed to image PFD bound to ends and surface of IAPP fibrils (Fig. 4), which 
reveals that the observed inhibition of the elongation and secondary nucleation pathways is achieved by these interactions (Fig. 5c). Only a low sub-stoichiometric PFD:IAPP ratio is required to obtain a major effect on the fibrillation kinetics, when inhibition is mediated by binding to fibrillar species ${ }^{50}$. The structures of fibrillar IAPP were elucidated recently by cryo$\mathrm{EM}^{11-15}$ One major polymorph observed contains two protofilaments with three $\beta$-strands each and has a pitch of $48 \mathrm{~nm}^{13-15}$. The fibril core is composed of residues 13-37 with residues 1-12 protruding from the fibril core which are therefore not resolved in the cryo-EM map due to their dynamic behaviour. This polymorph (PDB: 6Y1A) was used to model the PFD-IAPPfibril interaction as observed by EM, utilizing interacting IAPP and PFD residues identified by NMR to dock PFD and the fibril. This allowed us to get a sub-molecular insight into the interaction observed at low resolution by negative stain EM. From the fibril structure, it is clear that only the N-terminal binding epitope determined on IAPP is available for PFD binding when a fibril is formed. The PFD-IAPP fibril interaction through the N-terminal epitope was confirmed by the model obtained by NMR-guided docking ${ }^{48,49}$ (Fig. 5d,e). Yet, ca. up to six Ntermini of IAPP in its fibrillar state can fit into the PFD cavity when PFD is binding to the fibril surface or end, possibly leading to a higher affinity as compared to monomer binding. On the fibril end, the second binding site in the middle IAPP segment is additionally available to stabilize the interaction. According to EM, the PFD density at the fibril end was higher than on the lateral fibril surface. This suggests that the fibril end has a particularly high affinity for PFD, which can be explained by the fact that both IAPP segments important for interaction are exposed at the fibril end. The preference of PFD to bind to fibril ends correlated with the strong inhibition of fibril elongation observed in IAPP aggregation assays (Fig. 1). 
A striking effect of PFD on the IAPP fibrillation curves monitored by ThT FI was a decrease of the plateau height with addition of PFD (Fig 1). This could be due to a change in the fibrillar structure of IAPP leading to different binding of ThT molecules and subsequently decreased ThT FI, shielding of the surface due to PFD decoration, or due to the formation of less IAPP fibrils. A control experiment revealed that pure shielding of the ThT-IAPP fibril surface interaction by PFD is not sufficient to explain the amplitude of the observed effect (see material and methods section). However, AFM samples taken directly after termination of fibrillation assays show indeed decreased amounts of fibrils, but simultaneously, a morphological change in the observed aggregates is noticed. The fibrils which have formed in presence of PFD are shorter and cluster together, forming larger aggregates. The height profile and observed pitch, which can be measured on fibrils protruding from these aggregates in the AFM images, however are similar to the major polymorph formed in the absence of PFD. It seems that both decreased formation of aggregates and the formation of bigger clusters of aggregates, possibly also decorated by PFD molecules, lead to the observed effect in the ThT assays. The presence of PFD changes the amount and the length of fibrils and leads to their clustering. It is beyond the scope of this work to study changes in the toxicity of the aggregates formed in the presence of PFD, but it is worth noting that in the literature reduction of toxicity was observed upon decrease of the total exposed hydrophobicity by increase of aggregate size and surface shielding ${ }^{51,52}$.

In conclusion, in this study we demonstrated that both human and archaeal PFD are able to inhibit fibril formation of the amyloidogenic protein IAPP. Solution NMR enabled us to 
identify two binding regions on IAPP (from residues 10 to 19 and 24 to 28 ), and to map the corresponding binding sites within the PhPFD cavity. We established, using IAPP fibrillation assays and electron microscopy, that the sub-stoichiometric inhibition of IAPP fibrillation by PFD is mainly due to binding to fibril surface and ends, thereby inhibiting both secondary nucleation and elongation. Binding to the fibril is mediated by the N-terminal regions of IAPP of which up to six can be enclosed in the PFD cavity, interacting with PFDs coiled-coil helices. Binding to fibril ends is possibly supported by the second binding region, located in the middle segment of IAPP. The presence of PFD leads to the formation of lower amounts of aggregates, composed of shorter fibrils and clustered into formations of bigger size, which could be a potential detoxifying mechanism. 


\section{Material and Methods}

\section{Protein preparation}

IAPP. Human IAPP (H-KCNTATCATQ RLANFLVHSS NNFGAILSST NVGSNTY-NH

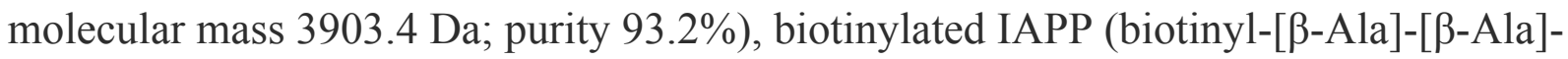
KCNTATCATQ RLANFLVHSS NNFGAILSST NVGSNTY-NH 2 ; molecular mass 4271.9 Da; purity 99.2\%), and DOTA $\left(2,2^{\prime}, 2^{\prime \prime}, 2^{\prime \prime \prime}-(1,4,7,10-\right.$ Tetraazacyclododecane-1,4,7,10-

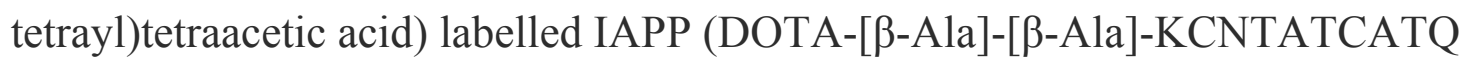
RLANFLVHSS NNFGAILSST NVGSNTY-NH all with an amidated $\mathrm{C}$ terminus and a disulfide bond between Cys2 and Cys7 were custom synthesized (Pepscan, Lelystad). Identity and purity were confirmed by RP-HPLC and mass spectrometry.

For kinetic experiments, to ensure monomeric starting material, the IAPP peptide powder was dissolved at $2 \mathrm{mg} \mathrm{ml}^{-1}$ in 1,1,1,3,3,3-hexafluoro-2-propanol (HFIP), incubated at room temperature for $1 \mathrm{~h}$ and lyophilized. Then $1 \mathrm{mg}$ peptide powder was dissolved in $0.5 \mathrm{ml}$ aqueous $6 \mathrm{M}$ guanidine hydrochloride solution, and size-exclusion chromatography was performed on a Superdex 75 Increase 10/300 column (GE Healthcare) equilibrated with $10 \mathrm{mM}$ 2-(N-morpholino)ethanesulfonic acid (MES)/ $\mathrm{NaOH}$ buffer, $\mathrm{pH}$ of 6.0 using an $\mathrm{NGC}$ liquid chromatography system (Bio-Rad). The monomer peak fraction was collected, aliquoted, flash frozen in liquid nitrogen, stored at $-80{ }^{\circ} \mathrm{C}$, and thawed on ice straight before further use. 
DOTA-functionalized IAPP was loaded with either paramagnetic $\mathrm{Gd}^{3+}$ or diamagnetic $\mathrm{Lu}^{3+}$ cations, respectively. Lyophilised DOTA-[ß-Ala]-[ß-Ala]-IAPP-NH 2 (400 $\mu \mathrm{g}, 90.2$ nmol) was dissolved in $500 \mu 120 \mathrm{mM}$ sodium acetate/acetic acid buffer $\mathrm{pH} 4.53$ and $18 \mu 1500 \mathrm{mM}$ aqueous $\mathrm{GaCl}_{3}$ solution was added (9 $\mu$ mol, i.e., a 100-fold molar excess). The solution was incubated at $25^{\circ} \mathrm{C}$ and $300 \mathrm{rpm}$ shaking. Time dependent $\mathrm{Gd}^{3+}$ loading was monitored by analysing the reaction mixture from withdrawn $10 \mu \mathrm{l}$ aliquots at different time points by RPHPLC on a $9.4 \mathrm{~mm}$ x $250 \mathrm{~mm}$ Zorbax 300SB-C8 column connected to a 1260 HPLC system (both Agilent) operated at a column temperature of $80{ }^{\circ} \mathrm{C}$, a flow rate of $4 \mathrm{ml} \mathrm{ml}^{-1}$ and UV absorbance monitoring at $214 \mathrm{~nm}$. A linear gradient from aqueous $8 \%(\mathrm{v} / \mathrm{v})$ acetonitrile (ACN), $0.1 \%(\mathrm{v} / \mathrm{v})$ trifluoroacetic acid (TFA) to $60 \%(\mathrm{v} / \mathrm{v}) \mathrm{ACN}, 0.1 \%(\mathrm{v} / \mathrm{v})$ TFA within 40 min was applied. $\mathrm{Gd}^{3+}$ loading was completed after $\sim 2 \mathrm{~h}$ and the remaining reaction mixture was subsequently purified by two to three consecutive preparative RP-HPLC runs (each 30 to 50 nmol $\mathrm{Gd}^{3+}$-DOTA-IAPP) under elution conditions described above.

Time dependent RP-HPLC analytics are shown in Supplementary Fig. 4a. Loading of DOTAIAPP with $\mathrm{Lu}^{3+}$ was performed in an analogous way (Supplementary Fig. 4b).

$\mathrm{U}-\left[{ }^{15} \mathrm{~N}\right]-$ or $\mathrm{U}-\left[{ }^{15} \mathrm{~N},{ }^{13} \mathrm{C}\right]$ isotopically labelled human IAPP was recombinantly expressed in Escherichia coli in M9 medium supplemented with either $2 \mathrm{~g} \mathrm{l}^{-1}{ }^{15} \mathrm{~N}-\mathrm{NH}_{4} \mathrm{Cl}$ and $3.2 \mathrm{~g}^{-1}$ nonlabeled glucose or with $2 \mathrm{~g} \mathrm{l}^{-1}{ }^{15} \mathrm{~N}-\mathrm{NH}_{4} \mathrm{Cl}$ and $\mathrm{U}-[13 \mathrm{C}]$ glucose and purified according to established protocols ${ }^{53}$. Purified recombinant IAPP from preparative RP-HPLC as final purification step was batch lyophilized, dissolved in HFIP, aliquoted and lyophilized again. Identity and purity (93\%) were confirmed by analytical RP-HPLC under isocratic conditions with $28.5 \%(\mathrm{v} / \mathrm{v}) \mathrm{ACN}, 0.1 \%(\mathrm{v} / \mathrm{v})$ TFA as mobile phase on a $4.6 \mathrm{~mm}$ x $250 \mathrm{~mm}$ Zorbax 
300SB-C8 column (Agilent) at $80{ }^{\circ} \mathrm{C}$ column temperature and $1 \mathrm{ml} \mathrm{min}^{-1}$ flow rate (Supplementary Fig. S4c). For quality control a 2D ${ }^{15} \mathrm{~N}-\mathrm{TROSY}$ spectrum of U-[ $\left.{ }^{15} \mathrm{~N}\right]-\mathrm{IAPP}$ was recorded at $10{ }^{\circ} \mathrm{C}$ on a NMR spectrometer with a ${ }^{1} \mathrm{H}$ frequency of $850 \mathrm{MHz}$ (Supplementary Fig. S4d).

Human Prefoldin (hPFD - 97.0 kDa). E. coli Rosetta2 (DE3) pLysS cells (Novagen) were transformed with pET-21a plasmids encoding for PFD1, PFD3, PFD5 and PFD6 ${ }^{54}$ or pET-41 (Genecust) encoding for PFD2 and PFD4 subunits of hPFD. The N-terminal 37 residues of PFD3 and four residues of PFD4 were deleted ${ }^{54}$, PFD2 and PFD4 contained N-terminal hexahistidine tags followed by a thrombin cleavage site (Supplementary Fig. S7a). Bacteria were either transformed with the plasmids for PFD1, PFD3, PFD5 and PFD6 individually or co-transformed with the plasmids for PFD2 and PFD3. The cells were grown at $30{ }^{\circ} \mathrm{C}$ in LBmedium with the required antibiotics (Chloramphenicol, Ampicillin, or Kanamycin). At $\mathrm{OD}_{600 \mathrm{~nm}}$ of 0.6 protein production was induced by IPTG $(1 \mathrm{mM})$ and the expression was performed at $20^{\circ} \mathrm{C}$ for $8 \mathrm{~h}(\mathrm{PFD} 1, \mathrm{PFD} 5), 30{ }^{\circ} \mathrm{C}$ for $4 \mathrm{~h}(\mathrm{PFD} 2, \mathrm{PFD} 3, \mathrm{PFD} 4)$ or $30{ }^{\circ} \mathrm{C}$ for $2 \mathrm{~h}$ (PFD6). All purification steps were carried out at $4{ }^{\circ} \mathrm{C}$. Cells expressing the different subunits were mixed (100 $\mathrm{ml}$ for PFD1, PFD5 or PFD2/PFD3, $150 \mathrm{ml}$ for PFD6 and $200 \mathrm{ml}$ for PFD4). Cells were sonicated in $50 \mathrm{ml}$ of $50 \mathrm{mM}$ sodium phosphate buffer $(\mathrm{pH} \mathrm{7})$, containing $300 \mathrm{mM}$ $\mathrm{NaCl}, 5 \mathrm{mM} \beta$-mercaptoethanol and complemented with $0.025 \mathrm{mg} / \mathrm{ml}$ RNAse (Euromedex), $0.025 \mathrm{mg} / \mathrm{ml}$ DNAse (Sigma Aldrich) and 1 anti-protease tablet (cOmplete ${ }^{\mathrm{TM}}$ ). Affinity purification, his-tag removal, cation exchange and size exclusion chromatography were performed as previously described. ${ }^{54}$ SEC-MALS and SDS-PAGE followed by Coomassie staining was used to monitor the purification process (Supplementary Fig. S6b,c). 
Prefoldin from Pyrococcus horikoshii (PhPFD - 86.4kDa). E. coli BL21 (DE3) cells transformed with pET23c plasmids encoding either for the $\alpha$ - or $\beta$-subunit of PFD from Pyrococcus horikoshii (point mutation on $\alpha$-subunit S98G) were used for protein expression (Supplementary Fig. S8a). To obtain unlabelled subunits, cells were grown at $37^{\circ} \mathrm{C}$ in LBmedium, at $\mathrm{OD}_{600 \mathrm{~nm}}$ of 0.8 protein production was induced by IPTG $(1 \mathrm{mM})$ and the expression was performed at $37^{\circ} \mathrm{C}$ for $3 \mathrm{~h}$. For production of $\mathrm{U}-\left[{ }^{2} \mathrm{H},{ }^{13} \mathrm{C},{ }^{15} \mathrm{~N}\right]-\mathrm{PhPFD}$ samples, cells were progressively adapted to $\mathrm{M} 9 / 2 \mathrm{H} 2 \mathrm{O}$ media in three stages over $24 \mathrm{~h}$. In the final culture the bacteria were grown at $37{ }^{\circ} \mathrm{C}$ in $\mathrm{M} 9$ media prepared with 99.85\% 2H2O (Eurisotop), $2 \mathrm{~g} / \mathrm{l}$ of $\mathrm{U}-\left[{ }^{2} \mathrm{H},{ }^{13} \mathrm{C}\right] \mathrm{D}$-glucose and $1 \mathrm{~g} /{ }^{15} \mathrm{NH}_{4} \mathrm{Cl}$ (Cambridge Isotope Laboratories). For production of $\left.\left.\mathrm{U}-\left[{ }^{2} \mathrm{H},{ }^{12} \mathrm{C},{ }^{15} \mathrm{~N}\right], \mathrm{A}-\left[{ }^{13} \mathrm{CH}_{3}\right]\right]^{\beta}, \mathrm{I}-\left[{ }^{13} \mathrm{CH}_{3}\right]{ }^{\delta 1}, \mathrm{~L}-\left[{ }^{13} \mathrm{CH}_{3}\right]^{\delta 2}, \mathrm{~V}-\left[{ }^{13} \mathrm{CH}_{3}\right]^{\gamma 2}, \mathrm{~T}-\left[{ }^{13} \mathrm{CH}_{3}\right]\right]^{\gamma 2}$ labelled subunits, 2 g/l of U- $\left[{ }^{2} \mathrm{H}\right]$ D-glucose (Sigma Aldrich) was used as carbon source. When the $\mathrm{OD}_{600 \mathrm{~nm}}$ reached 0.7 , a solution containing $240 \mathrm{mg} / 1$ of $2-\left[{ }^{13} \mathrm{C}\right] \mathrm{methyl}-4-\left[{ }^{2} \mathrm{H}_{3}\right]$-acetolactate (NMR-Bio) was added in $\mathrm{M} 9 /{ }^{2} \mathrm{H}_{2} \mathrm{O}$ media for the stereoselective labelling of pro-S Leu ${ }^{\delta 2}$ and $\mathrm{Val}^{\gamma 2}$ methyl groups ${ }^{55} .40$ min later 3-[ $\left.{ }^{13} \mathrm{C}\right]-2-\left[{ }^{2} \mathrm{H}\right]-\mathrm{L}-\mathrm{Alanine},(S)-2-$ hydroxy-2- $\left(2^{\prime}-\left[{ }^{13} \mathrm{C}\right], 1^{\prime}-\right.$ $\left.\left[{ }^{2} \mathrm{H}_{2}\right]\right)$ ethyl-3-oxo-4- $\left[{ }^{2} \mathrm{H}_{3}\right]$-butanoic acid (NMR-Bio) and 2,3- $\left({ }^{2} \mathrm{H}\right)$ 4- $\left({ }^{13} \mathrm{C}\right)$-L-Threonine (NMRBio) were added to a final concentration of $250 \mathrm{mg} / 1,100 \mathrm{mg} / 1$ and $50 \mathrm{mg} / 1$ respectively ${ }^{56,57}$ for the simultaneous labelling of $\mathrm{Ile}^{\delta 1}, \mathrm{Ala}^{\beta}, \mathrm{Thr}^{\gamma 2}$ methyl groups. Protein production was induced by IPTG $(1 \mathrm{mM})$ and protein expression was performed at $37^{\circ} \mathrm{C}$ for $3 \mathrm{~h}$. With such protocol, the level of deuteration of protein is higher than $97 \%$, while selectively labelled methyl probes are estimated to be protonated at more than $95 \%$. 
The purification protocol of archaeal prefoldin subunits was adapted from Okochi and coll. $^{58}$ as previously published ${ }^{38}$. SDS-PAGE followed by Coomassie staining, SEC-MALS and cryo-EM was used to control purity and homogeneity of produced samples (Supplementary Fig. S7b-d). Mass spectrometry was performed on the $\alpha$-subunits (data not shown). For interaction studies, the buffers of PhPFD- $\alpha_{2} \beta_{4}$ samples were exchanged for $25 \mathrm{mM} \mathrm{MES} / \mathrm{NaOH}$ buffer (pH 6.5), $25 \mathrm{mM}$ of $\mathrm{MgCl}_{2}$ using Amicon Centrifugal Filter Units (Merck).

\section{Thioflavin T (ThT)-fluorescence assays}

IAPP aggregation kinetics were monitored by ThT fluorescence intensity (FI). All the experimental solutions contained $5 \mu \mathrm{M}$ monomeric IAPP, $10 \mu \mathrm{M}$ ThT, and $6 \mathrm{mM} \mathrm{NaN}_{3}$ in 50 $\mathrm{mM}$ MES/NaOH (pH 6.5), $25 \mathrm{mM} \mathrm{MgCl}_{2}$. Each assay contained a row of IAPP:PFD ratios: a sample without PFD and 10 samples with different PFD concentrations corresponding to logarithmically equidistant molar ratios PFD:IAPP between 1:5000 and 1:1. De novo assays had no additional components. For seeded assays, pre-formed mature IAPP fibrils were added ( 8 to $9 \%$ of overall IAPP concentration in monomer equivalent): either non-sonicated in the secondary nucleation assay, or sonicated (Sonopuls MS 72 microtip sonotrode, Bandelin; 10\% amplitude, 4 cycles of $1 \mathrm{~s}$ pulse and $5 \mathrm{~s}$ break) in the elongation assay. For all assays, the samples were prepared as triplicates in protein LoBind tubes (Eppendorf) on ice and then transferred into a 96-well half-area polystyrene non-binding surface (NBS) microplate (3881, Corning). ThT FI values were recorded in a BMG FLUOstar Omega microplate reader (BMG LABTECH, Ortenberg) using excitation wavelengths of 448-10 nm and emission of 482-10 $\mathrm{nm}$, each data point corresponds to an orbitally averaged value over $3 \mathrm{~mm}$ with 20 flashes per 
well. In the de novo assays, $20 \mathrm{~s}$ orbital shaking at $300 \mathrm{rpm}$ before each cycle was applied as additional agitation.

Kinetic analysis was performed and parameters such as growth rate and growth acceleration were extracted by numerical approximation of first and second derivatives with respect to time of the ThT FI curve (Fig. 1a, Supplementary Fig. S1a). For the analysis of the elongation assays only the first linear parts of the curves were considered, since under the chosen conditions other aggregation mechanisms besides elongation start contributing to IAPP fibrillation from relatively early time-points.

Since in all kinetic assays the resulting final ThT FI plateau values were significantly lowered upon increasing PFD concentration, a control experiment was performed: after the completion of an aggregation assay, PFD concentrations were equalized in all the wells and then ThT FIs were re-measured. The difference in the plateau heights was preserved as before this manipulation. Hence, the change in the final plateau values cannot be simply attributed to PFD preventing ThT alignment on the fibrillar surface and its following fluorescence enhancement, but it rather reflects the amount of available fibrillar IAPP in solution (data not shown). For this reason, the kinetic analysis shown in Fig. 1a was performed on non-normalized data. However, the comparison of the changes in kinetic parameters extracted from normalized and nonnormalized data showed highly similar tendencies (Supplementary Fig. S1a), indicating the reliability of the conclusions on PFD inhibitory effects on IAPP aggregation.

Experimental data shown in Fig.1 for de novo and secondary nucleation assays were lag-timecorrected before averaging over the triplicates. Lag time, defined as the time before the first order time derivative reaches its 5 th percentile, varied in triplicates on average about $6 \%$. 
Exemplary comparison of modified and non-modified data is shown in Supplementary Fig.

S1b.

\section{AFM imaging}

For the AFM imaging, after recording de novo aggregation assays, the samples were taken out of the plate (96-well Half Area Black/Clear Flat Bottom Polystyrene NBS Microplate, Corning). The solution was extensively mixed in order to include the aggregates potentially sticking to the walls of the well. $2 \mu$ l of each sample were put onto a freshly cleaved muscovite mica surface and dried during the incubation over 10 minutes under the clean bench.

Subsequently, the samples were washed 3 times with $100 \mu \mathrm{l}$ Milli-Q $\mathrm{H}_{2} \mathrm{O}$ and dried with a steam of $\mathrm{N}_{2}$ gas. Imaging was performed in intermittent contact mode (AC mode) in a JPK NanoWizard 3 atomic force microscope (JPK, Berlin) using a silicon cantilever with silicon tip (OMCL-AC160TS-R3, Olympus) with a typical tip radius of $9 \pm 2 \mathrm{~nm}$, a force constant of 26 $\mathrm{N} / \mathrm{m}$ and resonance frequency around $300 \mathrm{kHz}$. The images were processed using JPK DP Data Processing Software (version spm-5.0.84). For the presented height profiles a polynomial fit was subtracted from each scan line first independently and then using limited data range. For each sample a net area of 2500-18400 $\mu^{2}$ was scanned for the overview, while part of it was additionally imaged with a higher resolution.

\section{Biolayer interferometry (BLI)}

The BLI measurements were conducted using BLItz-System (FortéBio, Sartorius), at room temperature. Super Streptavidin (SSA) biosensors (Sartorius) were hydrated in $50 \mathrm{mM}$ 
MES/NaOH (pH 6.5), 25 mM MgCl 2 buffer, loaded with biotinyl-[ $\beta$-Ala]-[ $\beta$-Ala]-IAPP-NH ${ }_{2}$ quenched with biotin to eliminate the nonspecific binding of PhPFD to biosensors, and equilibrated in buffer. The sensors were plunged in solutions containing different concentrations of PhPFD from $0.5 \mu \mathrm{M}$ to $150 \mu \mathrm{M}$ and the association curves were recorded over $180 \mathrm{~s}$, followed by the dissociation in the according buffer for $240 \mathrm{~s}$. The resulting binding kinetics were corrected using the blank reference, then a steady state analysis was performed using $R_{e q}=[A] R_{\max } /\left([A]+K_{D}\right)$ fitting equation, where $R_{e q}$ and $R_{\max }$ stay for equilibrium and maximum responses, and $[A]$ is analyte $(\mathrm{PhPFD})$ concentration.

\section{NMR spectroscopy}

IAPP-PFD titration. The NMR titration samples were prepared by adding unlabelled PhPFD into solutions of U-[ $\left.{ }^{15} \mathrm{~N}\right]$-labelled IAPP. Lyophilized, purified monomeric IAPP was suspended in an ice-cold buffer ( $25 \mathrm{mM} \mathrm{MES} / \mathrm{NaOH}(\mathrm{pH} 6.5), 25 \mathrm{mM} \mathrm{MgCl}_{2}$ ) at a concentration of 64 $\mu \mathrm{M}$ and aliquoted. The aliquots were flash-frozen in liquid nitrogen and stored at $-80{ }^{\circ} \mathrm{C}$. For every titration point the aliquots were thawed on ice; different amounts of PFD, buffer and $4 \mu 1$ of ${ }^{2} \mathrm{H}_{2} \mathrm{O}$ were added, so that the final concentration of IAPP was set to $29 \mu \mathrm{M}$ (total volume 44 $\mu 1)$. The ratios: 1:0 (apo), 1:0.4, 1:0.75, 1:1, 1:1.25, 1:2, 1:3, 1:4 and 1:8 were tested. Each sample was transferred into a $1.7 \mathrm{~mm}$ NMR tube and $2 \mathrm{D}{ }^{15} \mathrm{~N}$-SOFAST-HMQC spectra $^{59}$ were acquired at $30^{\circ} \mathrm{C}$ on a Bruker Avance III HD spectrometer equipped with a $1.7 \mathrm{~mm}$ cryogenic probe and operating at a ${ }^{1} \mathrm{H}$ frequency of $850 \mathrm{MHz}$. Data were processed using nmrPipe $/$ nmrDraw $^{60}$ and the $\mathrm{K}_{\mathrm{D}}$ and $\mathrm{k}_{\text {off }}$ were extracted using TITAN global lineshape fitting ${ }^{47}$ 
using NMR signals of residues A13, V17, H18, S19, F23, A25 and L27, assuming a 1:1

stoichiometry, therefore using the two-state binding model.

PhPFD assignment. Backbone atoms and methyl groups resonances of both $\alpha$ - and $\beta$-PhPFD subunits were previously assigned ${ }^{38}$, using a combination of (i) 3D BEST-TROSY HNCO, HNCA, HN(CA)CB, HN(CO)CA, HN(COCA)CB and HN(CA)CO experiments ${ }^{61}$; (ii) structure-based analysis of inter-methyl NOEs ${ }^{62}$; (iii) mutagenesis ${ }^{63}$ and (iv) 3D HCC-relay experiments $^{64,65}$ connecting backbone to methyl moieties. List of assigned chemical shifts is available online (BMRB accession code 50845) and annotated $2 \mathrm{D}{ }^{13} \mathrm{CH}_{3}$ - and ${ }^{15} \mathrm{~N}-\mathrm{TROSY}$ spectra $\left(70^{\circ} \mathrm{C}\right.$ in $50 \mathrm{mM}$ Tris $\left.(\mathrm{pH} 8.5), 100 \mathrm{mM} \mathrm{NaCl}\right)$ are presented on Supplementary Fig. S3. PRE-experiments. $200 \mu \mathrm{M}{ }^{15} \mathrm{~N}$ - or ${ }^{13} \mathrm{CH}_{3}$-labelled U- $\left[{ }^{2} \mathrm{H}\right]$-PhPFD sample was combined at a ratio of 1:1 (or 1:2 (for methyl labelled samples) with DOTA-modified IAPP loaded with $\mathrm{Lu}^{3+}$ (diamagnetic) or $\mathrm{Gd}^{3+}$ (paramagnetic) and transferred in $4 \mathrm{~mm}$ Shigemi tubes $(200 \mu \mathrm{l})$ ). For each sample 2D ${ }^{15} \mathrm{~N}$-BEST-TROSY ${ }^{66}$ or 2D SOFAST-METHYL-TROSY spectra ${ }^{63}$ were recorded at $30^{\circ} \mathrm{C}$ for $\sim 0.5$ day/sample on a Bruker Avance III HD spectrometer equipped with a cryogenic probe and operating at a ${ }^{1} \mathrm{H}$ frequency of $950 \mathrm{MHz}$. As a control experiment to exclude false positive interaction of PFD with the DOTA-cycle, we verified that addition of $\mathrm{Gd}^{3+}$-loaded DOTA to methyl-labelled PFD does not lead to specific residue broadening (Supplementary Fig. S9).

\section{Electron microscopy (EM)}

IAPP fibrils were formed by incubation of $64 \mu \mathrm{M}$ monomeric IAPP at room temperature for a minimum of one week in $10 \mathrm{mM}$ MES/ NaOH (pH 6.0). Concentrated purified PFD in $25 \mathrm{mM}$ 
MES/NaOH (pH 6.5) $25 \mathrm{mM} \mathrm{MgCl}_{2}$ was added in a ratio of 1:100 (PFD:IAPP-monomer concentration) and incubated for $30 \mathrm{~min}$. Samples were adsorbed to the clean side of a carbon film on mica, stained with sodium silicotungstate (SST) $\mathrm{Na}_{4} \mathrm{O}_{40} \mathrm{SiW}_{12}$ at $1 \%(\mathrm{w} / \mathrm{v})$ in distilled water (pH 7-7.5) and transferred to a 400-mesh copper grid $^{67}$. The images were taken under low dose conditions $\left(<30 \mathrm{e}^{-} / \AA^{2}\right)$ with defocus values between -1.2 and $-2.5 \mu \mathrm{m}$ on a FEI Tecnai $12 \mathrm{LaB} 6$ electron microscope at $120 \mathrm{kV}$ accelerating voltage, 30,000x nominal magnification using CCD Camera Gatan Orius 1000 and analysed with Gwyddion software ${ }^{68}$.

For cryo-EM imaging of PhPFD, 3.5 $\mu \mathrm{l}$ of PFD solution in $50 \mathrm{mMTris}, 100 \mathrm{mM} \mathrm{NaCl} \mathrm{pH=8.5}$ buffer at $100 \mu \mathrm{M}$ was blotted on a Quantifoil R2/2300 mesh gold grid coated with carbon and ionized by glow discharge. A FEI Vitrobot (automated vitrification machine) MARK IV was used at $6.5 \mathrm{sec}$ blotting time, $100 \%$ humidity at $20{ }^{\circ} \mathrm{C}$. About 1000 movies were recorded with a Thermo Scientific GLACIOS 200kV FEG with a Falcon II electron counting direct detection camera with EPU (automatic data collection) with a pixel size of $1.206 \AA$. About 700000 particles were extracted using guided particle picking, using the PhPFD crystal structure (PDB: 2ZDI). 2D classification was performed using relion standard procedures ${ }^{69}$.

\section{Modelling of IAPP-PhPFD complexes}

Interaction models were created by HADDOCK rigid model docking ${ }^{48}$, using the HADDOCK 2.4 web server ${ }^{49}$. For the model of the complex between monomeric IAPP and PhPFD, the basic docking protocol was used with the interaction residues on IAPP defined as the residues which showed above average chemical shift displacement upon PFD addition for most of the 
ratios (residues 6, 10-13, 17-19, 24, 26-28). The PhPFD interaction site was defined as residues which showed more than $50 \%$ of signal intensity loss upon interaction with paramagneticlabelled IAPP ( $\alpha$-subunit: 8, 9, 12, 20, 22, 24, 26, 29, 31, 37, 41, 65, 118, 125, 129, 132, 135 , 146; $\beta$-subunit: 4, 12, 15, 17, 22, 24, 26, 34, 46, 58, 81; $\beta$ '-subunit: 4, 12, 15, 17, 22, 24, 26, 34, 58, 61, 81, 107; Supplementary Fig. S5). The solution structure of IAPP in SDS micelles (PDB: 2L86) determined by $\mathrm{NMR}^{70}$ was used as the starting IAPP monomer conformation. Residues on the N-terminus of $\beta$-subunits missing in the PhPFD crystal structure (PDB: $2 Z D I)^{71}$ were obtained from molecular modelling (MODELLER ${ }^{72}$ ). For the complex involving PhPFD and IAPP fibril, the cryo-EM structure of the polymorph 1 of IAPP fibrils (PDB: 6Y1A) ${ }^{13}$ was used. The 12 missing N-terminal residues were added using molecular modelling $\left(M_{O D E L L E R}{ }^{72}\right.$ ), whereby a disulfide bond between residue two and seven was enforced. The same residues in PhPFD-IAPP monomer docking were used as restraints in PhPFD-IAPP fibril docking. For the fibril end interaction model, an IAPP fibril construct of 16 chains was used, and all the according residues on all the chains were given as docking restraints. To direct the docking towards the middle of the fibril, a longer IAPP fibril construct of 26 chains was used, and the interaction restraints were only set on the 18 chains in the middle of the construct. 


\section{Acknowledgments}

The authors thank Drs. Rida Awad and Leandro Estrozi for help and advices, Drs. K. Miki, M. Fujihashi and J.M. Valpuesta for providing clones of Prefoldin. This work used the high field NMR and EM facilities at the Grenoble Instruct-ERIC Center (ISBG; UAR 3518 CNRS-CEAUGA-EMBL) within the Grenoble Partnership for Structural Biology (PSB). Platform access was supported by FRISBI (ANR-10-INBS-05-02) and GRAL, a project of the University Grenoble Alpes graduate school (Ecoles Universitaires de Recherche) CBH-EUR-GS (ANR17-EURE-0003). The electron microscope facility is supported by the Auvergne-Rhône-Alpes Region, the Fondation pour la Recherche Médicale (FRM), the Fonds FEDER and the GISInfrastructures en Biologie Santé et Agronomie (IBiSA). IBS acknowledges integration into the Interdisciplinary Research Institute of Grenoble (IRIG, CEA). This work was supported by the French National Research Agency in the framework of the "Investissements d'avenir" program (ANR-15-IDEX-02). RT acknowledges a Ph.D. fellowship from Idex and FRM (FDT202012010629). WH acknowledges support from a European Research Council (ERC) Consolidator grant (no. 726368). LG and DW acknowledge support from the Russian Science Foundation (RSF) (project no. 20-64-46027) for isotopically or PRE-labelled IAPP preparation. 
Author contributions. D.W., J.B., R.T., T.K. and W.H. designed the experiments; R.T., T.K. \& L.G. prepared the samples; L.G., T.K., R.T. and W.H. performed and analyzed the ThT fluorescence assays, BLI and AFM experiments; E.C.D., J.B., P.G. and R.T. collected and analyzed the NMR experiments; D.F., G.S. and R.T. collected and analyzed the EM data. R.T. modelled the IAPP/PhPFD complexes; J.B., L.G., R.T., T.K. and W.H. wrote the manuscript. All authors discussed the results, corrected the manuscript and approved the final version of the paper.

Competing interests: The authors declare no competing financial interests. 


\section{References}

1. Iadanza, M. G., Jackson, M. P., Hewitt, E. W., Ranson, N. A. \& Radford, S. E. A new era for understanding amyloid structures and disease. Nature Reviews Molecular Cell Biology vol. 19 755-773 (2018).

2. Geddes, A. J., Parker, K. D., Atkins, E. D. T. \& Beighton, E. “Cross- $\beta$ ” conformation in proteins. Journal of Molecular Biology 32, 343-358 (1968).

3. Reiss, A. B., Arain, H. A., Stecker, M. M., Siegart, N. M. \& Kasselman, L. J. Amyloid toxicity in Alzheimer's disease. Reviews in the Neurosciences 29, 613-627 (2018).

4. Chiti, F. \& Dobson, C. M. Protein misfolding, amyloid formation, and human disease: A summary of progress over the last decade. Annual Review of Biochemistry vol. 86 27-68 (2017).

5. Westermark, P., Wernstedt, C., Wilander, E. \& Sletten, K. A novel peptide in the calcitonin gene related peptide family as an amyloid fibril protein in the endocrine pancreas. Biochemical and Biophysical Research Communications 140, 827-831 (1986).

6. Opie, E. L. The relation of diabetes mellitus to lesions of the pancreas. Hyaline degeneration of the islands of langerhans. Journal of Experimental Medicine 5, 527-540 (1901).

7. Westermark, P. Amyloid and polypeptide hormones: What is their interrelationship? Amyloid 1, 47-60 (1994).

8. Demuro, A. et al. Calcium dysregulation and membrane disruption as a ubiquitous neurotoxic mechanism of soluble amyloid oligomers. Journal of Biological Chemistry 280, 17294-17300 (2005).

9. Lashuel, H. A. \& Lansbury, P. T. Are amyloid diseases caused by protein aggregates that mimic bacterial pore-forming toxins? Quarterly Reviews of Biophysics vol. 39 167-201 (2006).

10. Janson, J., Ashley, R. H., Harrison, D., McIntyre, S. \& Butler, P. C. The mechanism of islet amyloid polypeptide toxicity is membrane disruption by intermediate-sized toxic amyloid particles. Diabetes 48, 491-498 (1999).

11. Cao, Q., Boyer, D. R., Sawaya, M. R., Ge, P. \& Eisenberg, D. S. Cryo-EM structure and inhibitor design of human IAPP (amylin) fibrils. Nature Structural and Molecular Biology 27, 653-659 (2020).

12. Cao, Q. et al. Cryo-EM structures of hIAPP fibrils seeded by patient-extracted fibrils reveal new polymorphs and conserved fibril cores. Nature Structural \& Molecular Biology 28, 724-730 (2021).

13. Röder, C. et al. Cryo-EM structure of islet amyloid polypeptide fibrils reveals similarities with amyloid- $\beta$ fibrils. Nature Structural and Molecular Biology 27, 660-667 (2020).

14. Gallardo, R. et al. Fibril structures of diabetes-related amylin variants reveal a basis for surfacetemplated assembly. Nature Structural and Molecular Biology 27, 1048-1056 (2020).

15. Kapurniotu, A. Enlightening amyloid fibrils linked to type 2 diabetes and cross-interactions with A $\beta$. Nature Structural and Molecular Biology vol. 27 1006-1008 (2020).

16. Labbadia, J. \& Morimoto, R. I. The biology of proteostasis in aging and disease. Annual Review of Biochemistry vol. 84 435-464 (2015).

17. Olzscha, H. et al. Amyloid-like aggregates sequester numerous metastable proteins with essential cellular functions. Cell 144, 67-78 (2011).

18. Padrick, S. B. \& Miranker, A. D. Islet amyloid: Phase partitioning and secondary nucleation are central to the mechanism of fibrillogenesis. Biochemistry 41, 4694-4703 (2002).

19. Willbold, D., Strodel, B., Schröder, G. F., Hoyer, W. \& Heise, H. Amyloid-type Protein Aggregation and Prion-like Properties of Amyloids. Chemical Reviews 121, (2021).

20. Wentink, A., Nussbaum-Krammer, C. \& Bukau, B. Modulation of amyloid states by molecular chaperones. Cold Spring Harbor Perspectives in Biology 11, (2019). 
21. Du, Y. et al. HDAC6-mediated Hsp90 deacetylation reduces aggregation and toxicity of the protein alpha-synuclein by regulating chaperone-mediated autophagy. Neurochemistry International 149, 105141 (2021).

22. Chaudhuri, T. K. \& Paul, S. Protein-misfolding diseases and chaperone-based therapeutic approaches. FEBS Journal vol. 273 1331-1349 (2006).

23. Linse, S., Thalberg, K. \& Knowles, T. P. J. The unhappy chaperone. QRB Discovery 2, (2021).

24. Macošek, J., Mas, G. \& Hiller, S. Redefining Molecular Chaperones as Chaotropes. Frontiers in Molecular Biosciences 8, 514 (2021).

25. Arosio, P. et al. Kinetic analysis reveals the diversity of microscopic mechanisms through which molecular chaperones suppress amyloid formation. Nature Communications 7, 1-9 (2016).

26. Nachman, E. et al. Disassembly of Tau fibrils by the human Hsp70 disaggregation machinery generates small seeding-competent species. Journal of Biological Chemistry 295, 9676-9690 (2020).

27. Wentink, A. S. et al. Molecular dissection of amyloid disaggregation by human HSP70. Nature 587, 483-488 (2020).

28. Gonçalves, C. C., Sharon, I., Schmeing, T. M., Ramos, C. H. I. \& Young, J. C. The chaperone HSPB1 prepares protein aggregates for resolubilization by HSP70. Scientific Reports 11, 1-16 (2021).

29. Jinwal, U. K. et al. Hsc70 rapidly engages tau after microtubule destabilization. Journal of Biological Chemistry 285, 16798-16805 (2010).

30. Mainz, A. et al. The chaperone $\alpha b$-crystallin uses different interfaces to capture an amorphous and an amyloid client. Nature Structural and Molecular Biology 22, 898-905 (2015).

31. Cohen, S. I. A. et al. Proliferation of amyloid- $\beta 42$ aggregates occurs through a secondary nucleation mechanism. Proceedings of the National Academy of Sciences of the United States of America 110, 9758-9763 (2013).

32. Siegert, R., Leroux, M. R., Scheufler, C., Hartl, F. U. \& Moarefi, I. Structure of the Molecular Chaperone Prefoldin. Cell 103, 621-632 (2000).

33. Lundin, V. F. et al. Molecular clamp mechanism of substrate binding by hydrophobic coiled-coil residues of the archaeal chaperone prefoldin. Proceedings of the National Academy of Sciences of the United States of America 101, 4367-72 (2004).

34. Sakono, M., Zako, T., Ueda, H., Yohda, M. \& Maeda, M. Formation of highly toxic soluble amyloid beta oligomers by the molecular chaperone prefoldin. FEBS Journal 275, 5982-5993 (2008).

35. Sörgjerd, K. M. et al. Human prefoldin inhibits amyloid- $\beta$ (A $\beta)$ fibrillation and contributes to formation of nontoxic A $\beta$ aggregates. Biochemistry 52, 3532-3542 (2013).

36. Tashiro, E. et al. Prefoldin protects neuronal cells from polyglutamine toxicity by preventing aggregation formation. Journal of Biological Chemistry 288, 19958-19972 (2013).

37. Takano, M. et al. Prefoldin prevents aggregation of $\alpha$-synuclein. Brain Research 1542, 186-194 (2014).

38. Törner, R. et al. Backbone and methyl resonances assignment of the $87 \mathrm{kDa}$ prefoldin from Pyrococcus horikoshii. Biomolecular NMR Assignments 2021 1-10 (2021) doi:10.1007/S12104021-10029-4.

39. Martín-Benito, J. et al. Structure of eukaryotic prefoldin and of its complexes with unfolded actin and the cytosolic chaperonin CCT. EMBO Journal 21, 6377-6386 (2002).

40. Gestaut, D. et al. The chaperonin TRiC/CCT associates with Prefoldin through a conserved electrostatic interface essential for cellular proteostasis. Cell 177, 751-765 (2019).

41. Mas, G. et al. Structural investigation of a chaperonin in action reveals how nucleotide binding regulates the functional cycle. Science Advances 4, 4196 (2018). 
42. Iwahara, J., Schwieters, C. D. \& Clore, G. M. Ensemble Approach for NMR Structure Refinement against 1H Paramagnetic Relaxation Enhancement Data Arising from a Flexible Paramagnetic Group Attached to a Macromolecule. Journal of the American Chemical Society 126, 5879-5896 (2004).

43. Battiste, J. L. \& Wagner, G. Utilization of site-directed spin labeling and high-resolution heteronuclear nuclear magnetic resonance for global fold determination of large proteins with limited nuclear overhauser effect data. Biochemistry 39, 5355-5365 (2000).

44. He, L. \& Hiller, S. Frustrated Interfaces Facilitate Dynamic Interactions between Native Client Proteins and Holdase Chaperones. ChemBioChem 20, 2803-2806 (2019).

45. Hiller, S. \& Burmann, B. M. Chaperone-client complexes: A dynamic liaison. Journal of Magnetic Resonance 289, 142-155 (2018).

46. Karagöz, G. E. et al. Hsp90-tau complex reveals molecular basis for specificity in chaperone action. Cell 156, 963-974 (2014).

47. Waudby, C. A., Ramos, A., Cabrita, L. D. \& Christodoulou, J. Two-Dimensional NMR Lineshape Analysis. Scientific Reports 6, 24826 (2016).

48. Dominguez, C., Boelens, R. \& Bonvin, A. M. J. J. HADDOCK: A protein-protein docking approach based on biochemical or biophysical information. Journal of the American Chemical Society 125, 1731-1737 (2003).

49. van Zundert, G. C. P. et al. The HADDOCK2.2 Web Server: User-Friendly Integrative Modeling of Biomolecular Complexes. Journal of Molecular Biology 428, 720-725 (2016).

50. Cohen, S. I. A. et al. A molecular chaperone breaks the catalytic cycle that generates toxic A $\beta$ oligomers. Nature Structural and Molecular Biology 22, 207-213 (2015).

51. Ojha, J., Masilamoni, G., Dunlap, D., Udoff, R. A. \& Cashikar, A. G. Sequestration of Toxic Oligomers by HspB1 as a Cytoprotective Mechanism. Molecular and Cellular Biology 31, 3146-3157 (2011).

52. Mannini, B. et al. Molecular mechanisms used by chaperones to reduce the toxicity of aberrant protein oligomers. Proceedings of the National Academy of Sciences of the United States of America 109, 12479-12484 (2012).

53. Mirecka, E. A. et al. Engineered aggregation inhibitor fusion for production of highly amyloidogenic human islet amyloid polypeptide. Journal of Biotechnology 191, 221-227 (2014).

54. Aikawa, Y., Kida, H., Nishitani, Y. \& Miki, K. Expression, purification, crystallization and Xray diffrection of the molecular chaperone prefoldin from Homo sapiens. research communications Acta Cryst 71, 1189-1193 (2015).

55. Gans, P. et al. Stereospecific Isotopic Labeling of Methyl Groups for NMR Spectroscopic Studies of High-Molecular-Weight Proteins. Angewandte Chemie International Edition 49, 1958-1962 (2010).

56. Kerfah, R., Plevin, M. j., Sounier, R., Gans, P. \& Boisbouvier, J. Methyl Specific Isotopic Labeling: A Molecular Tool Box for NMR Studies of Large Proteins Authors: Current Opinion in Structural Biology (2015).

57. Ayala, I. et al. Asymmetric Synthesis of Methyl Specifically Labelled $L$ - Threonine and Application to the NMR Studies of High Molecular Weight Proteins. ChemistrySelect 5, 50925098 (2020).

58. Okochi, M. et al. Pyrococcus prefoldin stabilizes protein-folding intermediates and transfers them to chaperonins for correct folding. Biochemical and Biophysical Research Communications 291, 769-774 (2002). 
59. Schanda, P. \& Brutscher, B. Very fast two-dimensional NMR spectroscopy for real-time investigation of dynamic events in proteins on the time scale of seconds. Journal of the American Chemical Society 127, 8014-8015 (2005).

60. Delaglio, F. et al. NMRPipe: A multidimensional spectral processing system based on UNIX pipes. Journal of Biomolecular NMR 6, 277-293 (1995).

61. Favier, A. \& Brutscher, B. NMRlib: user-friendly pulse sequence tools for Bruker NMR spectrometers. Journal of Biomolecular NMR 73, 199-211 (2019).

62. Monneau, Y. R. et al. Automatic methyl assignment in large proteins by the MAGIC algorithm. Journal of Biomolecular NMR 69, 215-227 (2017).

63. Amero, C. et al. Fast Two-Dimensional NMR Spectroscopy of High Molecular Weight Protein Assemblies. Journal of the American Chemical Society 131, 3448-3449 (2009).

64. Tugarinov, V. \& Kay, L. E. Methyl Groups as Probes of Structure and Dynamics in NMR Studies of High-Molecular-Weight Proteins. ChemBioChem 6, 1567-1577 (2005).

65. Henot, F. et al. Optimized precursor to simplify assignment transfer between backbone resonances and stereospecifically labelled valine and leucine methyl groups: application to human Hsp90 N-terminal domain. Journal of Biomolecular NMR 2021 75:6 75, 221-232 (2021).

66. Lescop, E., Schanda, P. \& Brutscher, B. A set of BEST triple-resonance experiments for timeoptimized protein resonance assignment. Journal of Magnetic Resonance 187, 163-169 (2007).

67. Valentine, R. C., Shapiro, B. M. \& Stadtman, E. R. Regulation of Glutamine Synthetase. XII. Electron Microscopy of the Enzyme from Escherichia coli. Biochemistry 7, 2143-2152 (1968).

68. Nečas, D. \& Klapetek, P. Gwyddion: An open-source software for SPM data analysis. Central European Journal of Physics vol. 10 181-188 (2012).

69. Scheres, S. H. W. A bayesian view on cryo-EM structure determination. Journal of Molecular Biology (2012) doi:10.1016/j.jmb.2011.11.010.

70. Nanga, R. P. R., Brender, J. R., Vivekanandan, S. \& Ramamoorthy, A. Structure and membrane orientation of IAPP in its natively amidated form at physiological $\mathrm{pH}$ in a membrane environment. Biochimica et Biophysica Acta - Biomembranes 1808, 2337-2342 (2011).

71. Ohtaki, A., Noguchi, K. \& Yohda, M. Structure and function of archaeal prefoldin, a cochaperone of group II chaperonin. Frontiers in Bioscience 15, 708-717 (2010).

72. Šali, A. \& Blundell, T. L. Comparative Protein Modelling by Satisfaction of Spatial Restraints. Journal of Molecular Biology 234, 779-815 (1993).

73. Baker, N. A., Sept, D., Joseph, S., Holst, M. J. \& McCammon, J. A. Electrostatics of nanosystems: Application to microtubules and the ribosome. Proceedings of the National Academy of Sciences of the United States of America 98, 10037-10041 (2001).

74. Rullgård, H., Öfverstedt, L. G., Masich, S., Daneholt, B. \& Öktem, O. Simulation of transmission electron microscope images of biological specimens. Journal of Microscopy 243, 234-256 (2011). 


\section{Figures Legends:}

\section{Figure 1. Inhibition of IAPP aggregation by Prefoldin.}

a) IAPP aggregation kinetics in absence and presence of various concentrations of PhPFD (left column) and hPFD (middle column) with [PFD]:[IAPP] molar ratios ranging from 1:5000 to 1:1, followed by ThT fluorescence intensity (FI). Top row: de novo aggregation assay, where the aggregation starts from monomeric IAPP only, in presence of agitation. Middle row: secondary nucleation assay, where the aggregation starts from the mixture of monomeric IAPP and non-sonicated preformed IAPP fibrils (seeds), with no agitation. Bottom row: elongation assay, showing non-agitated aggregation of monomeric IAPP in presence of shorter sonicated seeds, where the initial linear parts of the curves (inset) are reflecting pure elongation of fibril seeds. The right column shows extracted kinetic parameters of changes in IAPP aggregation assays: growth phase duration, maximal growth rate, and initial growth rate for the according aggregation assays. Further kinetic analysis is presented in Supplementary Fig. S1a. b) AFM images of the samples at the end of the aggregation kinetic assays shown in section a (top row). Fibrils of IAPP $(5 \mu \mathrm{M})$ aggregated in absence of PFD, rare clustered aggregates of IAPP formed in presence of $0.76 \mu \mathrm{M}$ and $5 \mu \mathrm{M}$ of PhPFD or hPFD (1:6.6 and 1:1 [PFD]:[IAPP] ratios accordingly). Each square image represents an area of $2 \times 2 \mu \mathrm{m}^{2}$. In order to visualize objects decidedly differing in height, two colour code scales were used: the gradient from dark brown to white represents either $0 \mathrm{~nm}$ to $60 \mathrm{~nm}$ height, or $0 \mathrm{~nm}$ to $1 \mathrm{~nm}$ (highlighted in grey). The full AFM overview is presented in Supplementary Figure S2, including inter alia the control sample containing PFD alone and illustrating that the carpet-like coverage of the 
surface with small roundish particles at increased PFD concentration is the appearance of PFD itself.

\section{Figure 2: Binding sites of IAPP on PhPFD structures}

a) PRE-labelled IAPP was obtained by fusion of a DOTA-macrocycle to the N-terminus of IAPP and subsequent loading of DOTA with $\mathrm{Lu}^{3+}$ (diamagnetic control) or $\mathrm{Gd}^{3+}$ (paramagnetic). Line broadening resulting from the proximity of Gd-IAPP (red spectra), compared to the control Lu-IAPP (blue spectra), is visible in $2 \mathrm{D}{ }^{15} \mathrm{~N}$-TROSY spectrum of $\beta$ subunit (b), 2D ${ }^{13} \mathrm{CH}_{3}$-TROSY spectrum of $\beta$-subunit (c), $2 \mathrm{D}{ }^{15} \mathrm{~N}$-TROSY spectrum of the $\alpha$ subunit (d), and ${ }^{13} \mathrm{CH}_{3}$-TROSY spectrum of the $\alpha$-subunit of PFD (e). A partial peak doubling is observed for the $\beta$ subunits, due to their position in the PFD heterohexameric complex, some of which could be assigned to $\beta$ and $\beta^{, 38}$ (panels b and $c$ ), while the two $\alpha$-subunits are spectroscopically equivalent (panels $d$ and e). f) Model of PhPFD (PDB: 2zdi) with $\alpha$-subunits in blue, $\beta$-subunits in green. g) No line-broadening was observed for residues on the top of the PFD complex. Conversely a strong effect was observed inside the cavity (j) and along the elongated coiled-coil helices of (h) $\beta / \beta^{\prime}$-subunits (two views related by $180^{\circ}$ rotation) and (i) $\alpha$ subunits dimer (side view).

\section{Figure 3: Interaction of monomeric IAPP with Prefoldin}

a) Extracts of $2 \mathrm{D}{ }^{15} \mathrm{~N}-\mathrm{SOF} A \mathrm{ST}-\mathrm{HMQC}$ spectra of IAPP titration by addition of PhPFD. [PhPFD]:[IAPP] molar ratios ranging of $0,0.3,0.75$, and 1.25 are shown. b) Fit of $\mathrm{K}_{\mathrm{D}}$ signals of A13, V17, H18, S19, F23, A25 and L27. c) Summary of detected chemical shift 
perturbations (CSPs) $\Delta \delta$ (calculated as $\Delta \delta=\sqrt{\Delta N^{2}+\Delta H^{2}}$ ) induced by addition of a two-fold

excess of PFD on uniformly ${ }^{15} \mathrm{~N}$-labelled sample of IAPP. d) Peak broadening of IAPP signals upon addition of PhPFD, calculated as the intensity ratio of $\mathrm{NH}$ signals in IAPP/PhPFD complex (I) and in absence of PhPFD $\left(\mathrm{I}_{0}\right)$. Asterisk denotes values obtained at $10^{\circ} \mathrm{C}$ due to peak overlap at $30^{\circ} \mathrm{C}$. e) IAPP sequence with colour coding of detected CSPs at ratio 1:2 (residue with above average $\Delta \delta$, that is $\geq 0.12 \mathrm{ppm}$ in red) and line broadening at ratio $1: 2$ (residue with $\mathrm{I} / \mathrm{I}_{0} \leq 0.26$ in yellow). f) Steady state analysis of biolayer interferometry (BLI) experiment on PhPFD binding to monomeric IAPP: measured values (dark blue) and fit (light blue

\section{Figure 4: EM images of PhPFD bound to IAPP fibrils}

a) Electron microscopy images of IAPP fibrils, stained with sodium silicotungstate (SST) at 30,000x magnification. b-c) Close up of main fibril species. d) Molecular model of polymorph 1 of the IAPP fibril (PDB: 6Y1A $)^{13}$. e) Preformed fibrils $(67 \mu \mathrm{M})$ were incubated with PhPFD in a ratio of 100:1 (IAPP monomer equivalent concentrations) for 30 min and imaged under the same conditions as IAPP fibrils (a). Decoration of the fibril surface with PhPFD is observed, remaining PhPFD particles are observed in the background. f-h) Close-ups of the fibrils show the decoration of the fibril surface (pink arrows) and end (white arrows). i) Molecular model corresponding to the observed fibril decoration. Horizontal white and black bars correspond to a length of $100 \mathrm{~nm}$ and $10 \mathrm{~nm}$, respectively. Simulated TEM images of (d) and (i) are shown in Supplementary Fig. S10. 


\section{Figure 5: Structural Model of inhibition of IAPP fibril formation by PFD}

Schematic model describing the inhibition mechanism of PFD on IAPP fibril formation. PFD interacts with monomeric IAPP but this transient interaction does not lead to a significant decrease of the lag-phase. (a) and (b) present docking models of the complex between monomeric IAPP (PDB: 2L86) and PhPFD (PDB: 2ZDI) based on NMR derived interaction information (Fig. 2, 3). c) Inhibition of secondary nucleation and elongation results from coverage of fibril surface and ends by PFD (Fig. 4). The presence of PFD leads to a decreased steady phase fibril mass (Fig. 1a), which results from the formation of less aggregates with an altered morphology (Fig. 1b). The inset zoom represents a model of IAPP fibril structure with unfolded residues 1 to 12 in yellow and the structured fibril core is represented in purple (from residues 13 to 37). (d) and (e) present docking models of PhPFD (PDB: 2ZDI) on IAPP fibril (PDB: 6Y1A) surface and extremities, respectively, integrating structural information obtained by NMR (Fig. 2, 3) and EM (Fig. 4); the black arrows indicate the fibril axis with the tips pointing towards the fibril ends. 
bioRxiv preprint doi: https://doi.org/10.1101/2021.10.20.465084 this version posted October 20,2021 . The copyright holder for this preprint (which was not certified by peer review) is the author/funder, who has granted bioRxiv a license to display the preprint in perpetuity. It is made available under aCC-BY-NC-ND 4.0 International license.

\section{Figure 1}
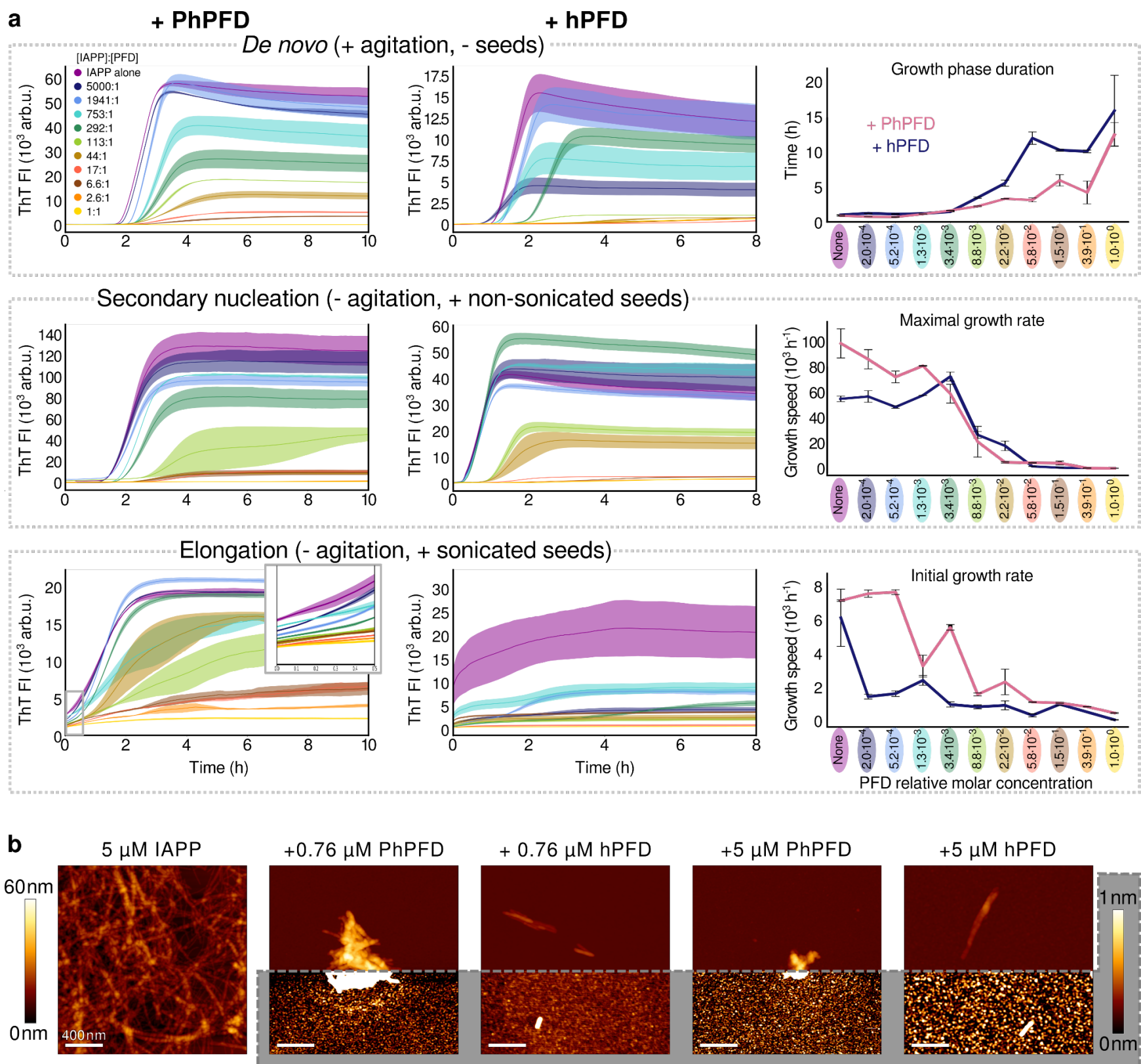
bioRxiv preprint doi: https://doi.org/10.1101/2021.1020.465084 this version posted October 20,2021. The copyright holder for this preprint (which was not certified by peer review) is the author/funder, who has granted bioRxiv a license to display the preprint in perpetuity. It is made available under aCC-BY-NC-ND 4.0 International license.

Figure 2

a

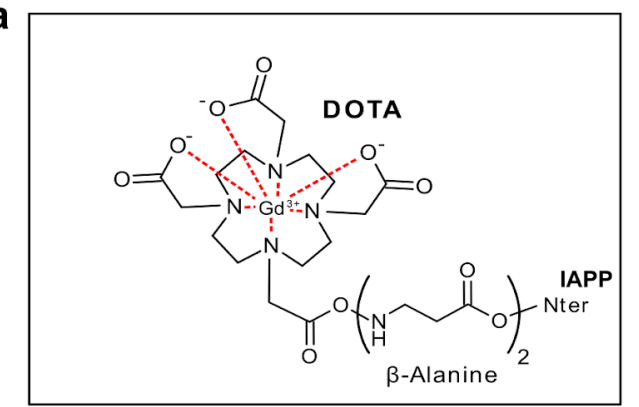

b

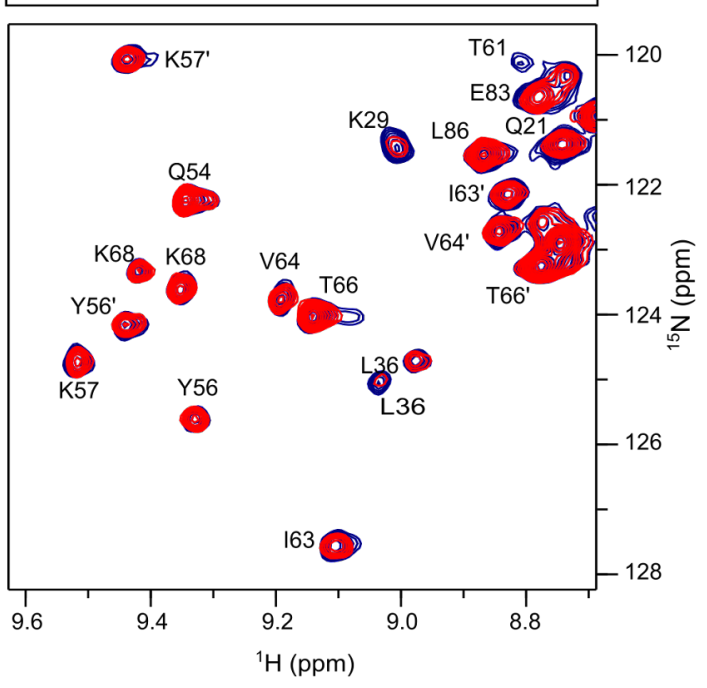

g topview

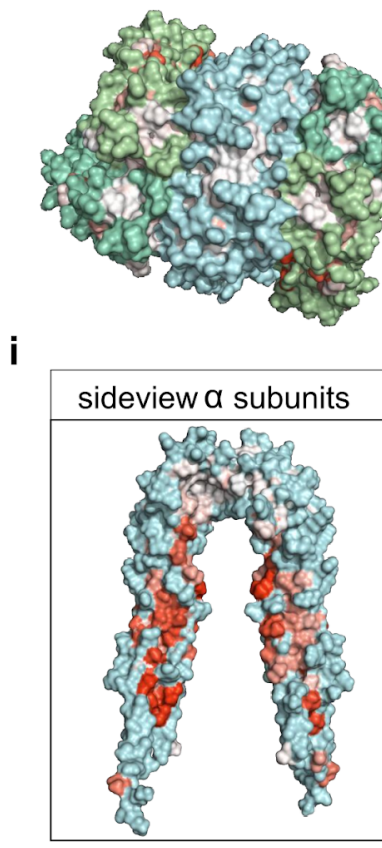

C

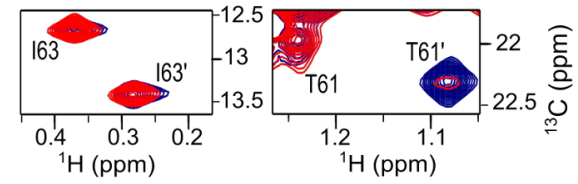

d
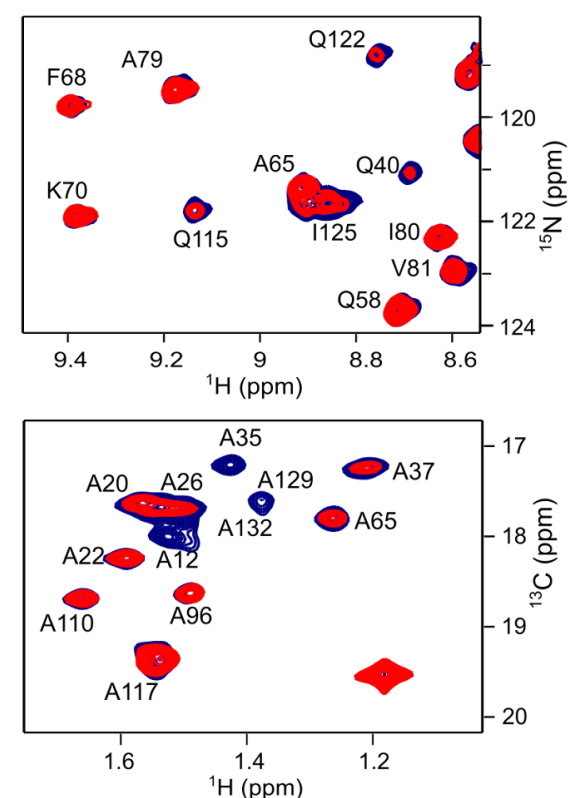

h

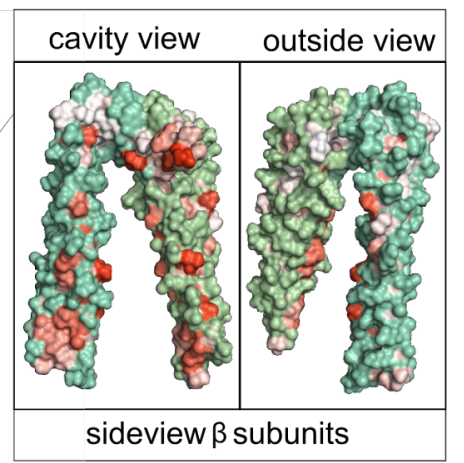

sideview $\beta$ subunits

\section{j cavity}

PRE-effect 
bioRxiv preprint doi: https://doi.org/10.1101/2021.10.20.465084; this version posted October 20, 2021. The copyright holder for this preprint (which was not certified by peer review) is the author/funder, who has granted bioRxiv a license to display the preprint in perpetuity. It is made available under aCC-BY-NC-ND 4.0 International license.

Figure 3

a

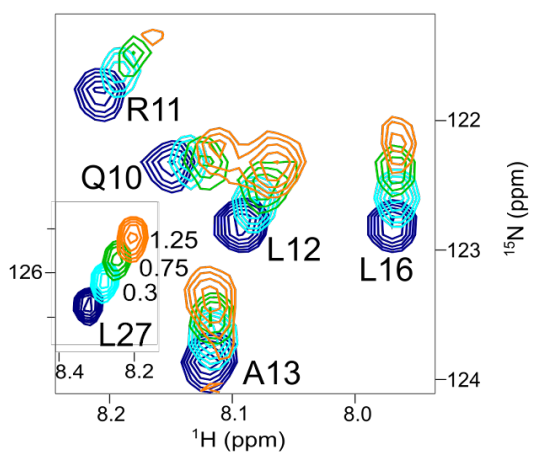

b
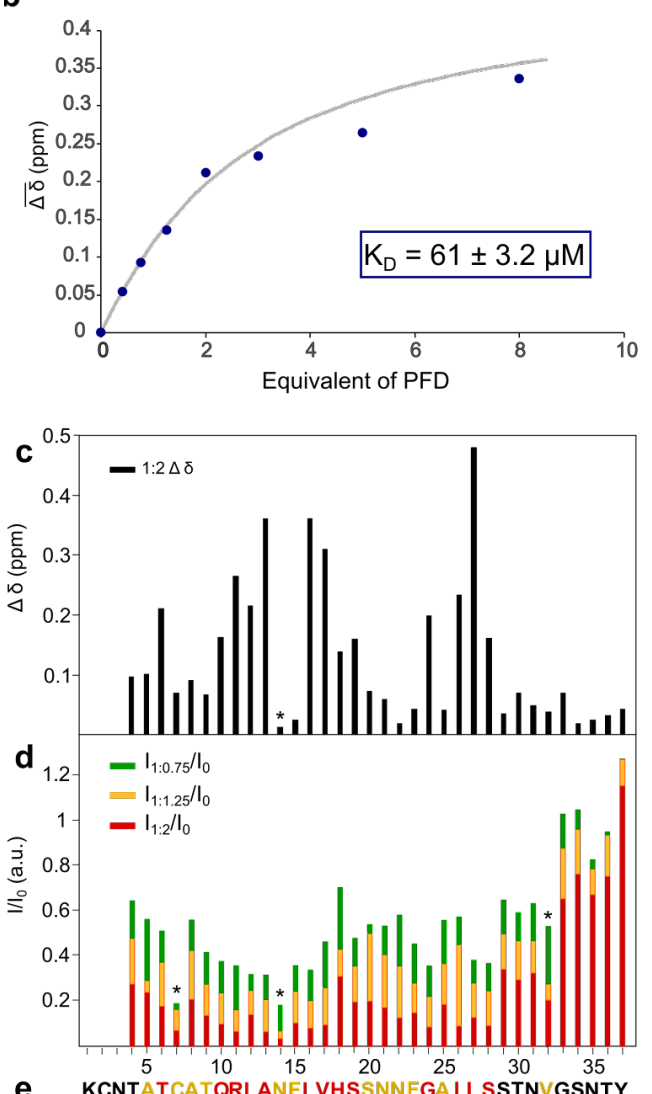

e KCNTATCATQRLANFLVHSSNINFGA

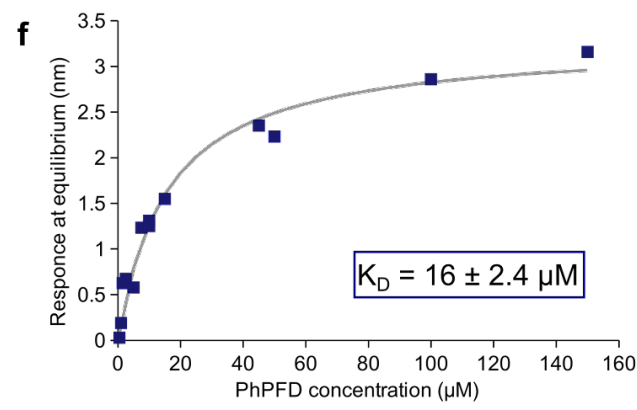


bioRxiv preprint doi: https://doi.org/10.1101/2021.1020.465084 this version posted October 20,2021. The copyright holder for this preprint (which was not certified by peer review) is the author/funder, who has granted bioRxiv a license to display the preprint in perpetuity. It is made available under aCC-BY-NC-ND 4.0 International license.

\section{Figure 4}
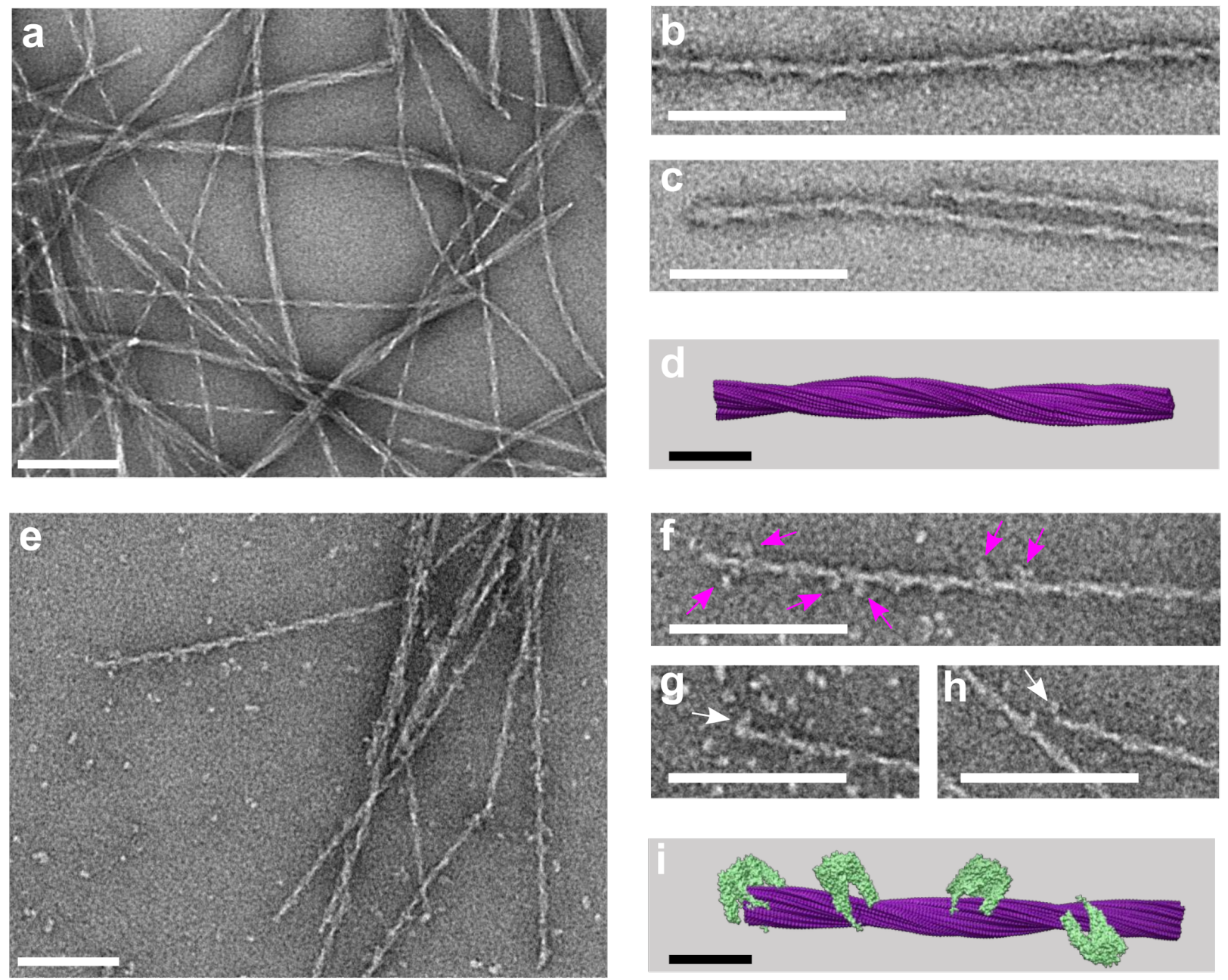
bioRxiv preprint doi: https://doi.org/10.1101/2021.1020.465084 * this version posted October 20, 2021. The copyright holder for this preprint (which was not certified by peer review) is the author/funder, who has granted bioRxiv a license to display the preprint in perpetuity. It is made available under aCC-BY-NC-ND 4.0 International license.

\section{Figure 5}

Monomer interaction model

a

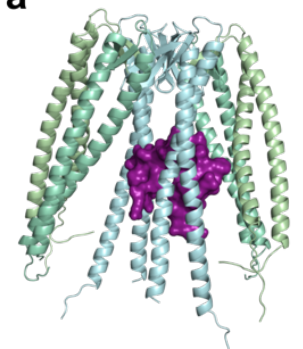

b

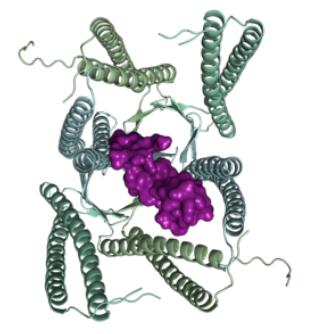

C
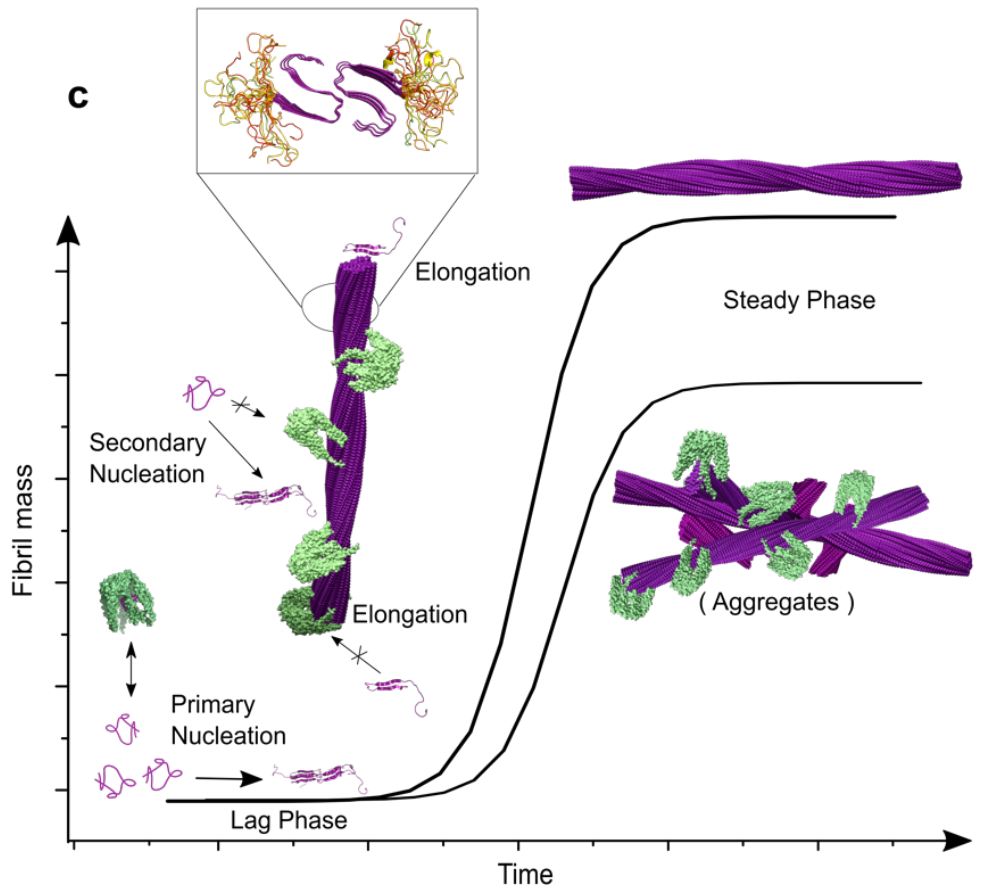

Fibril interaction model

d

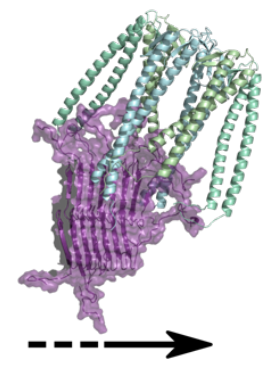

e

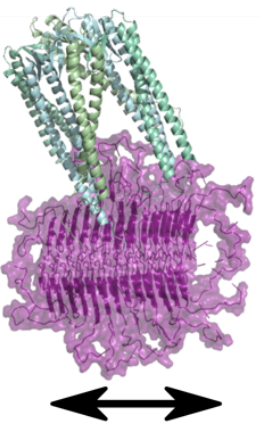

